\title{
Microcontroller Based Home Security and Load Controlling Using Gsm Technology
}

\author{
Mustafijur Rahman \\ Dept of EEE, University of Asia Pacific Dhanmondi, Dhaka-1209, Bangladesh \\ Email: Shojib.uap13@gmail.com
}

\author{
A.H.M Zadidul Karim \\ Assistant Professor, Dept of EEE, University of Asia Pacific Dhanmondi, Dhaka-1209, Bangladesh \\ Email-zadidkarim@gmail.com \\ Sultanur Nyeem \\ Dept of EEE, University of Asia Pacific Dhanmondi, Dhaka-1209, Bangladesh \\ Email: rupom.uap11@gmail.com \\ Faisal Khan \\ Dept of EEE, University of Asia Pacific Dhanmondi, Dhaka-1209, Bangladesh \\ Email: faisal803eee@gmail.com \\ Golam Matin \\ Dept of EEE, University of Asia Pacific Dhanmondi, Dhaka-1209, Bangladesh \\ Email: sumon.matin@gmail.com
}

\begin{abstract}
Home automation" referred to as 'Intelligent home' or 'automated home', indicates the automation of daily tasks with electrical devices used in homes. This could be the control of lights or more complex chores such as remote viewing of the house interiors for surveillance purposes. The emerging concept of smart homes offers a comfortable, convenient and safe and secure environment for occupants. These include automatic load controlling, fire detection, temperature sensing, and motion detection and lock system etc. Furthermore it has advanced security compared to other houses and can send a message to the user for action that occur inside his/her house while he/she is away from home. It can also allow a person to control appliances from a remote location by mobile phone using GSM technology.
\end{abstract}

Index Terms - Home automation, Load controlling, Fire detection, Temperature sensing, Motion detection, Lock system, GSM technology.

\section{INTRODUCTION}

As technology is advancing, so houses are also getting smarter. Modern houses are gradually shifting from conventional switches to centralized control system. Smart home automations gives the owner of a home an ultimate control over his or her home by automating lighting system, dimming, electrical appliances. Smart automated homes connect all the devices and appliances in user's home so they can communicate with each other.
This advanced technology is used to do automation of a house activities, so it is also can be called as home automation [1], [2].

A smart home can be controlled by remote interface to home automation system itself via wireless technology [3], [4], [5]. A smart home automation can turn on and off a fan, light, air condition and also can control the speed of fan with the help of a mobile controller according to user needs. Because mobile controlled home automation system provides a simpler solution of a GSM network [6], [7]. It will help to shut down the whole system, improves the convenience and comfort of the user while it provides security and energy efficiency. GSM is used to digitalize a signal or data and transmit signal or data to the receiver. GSM (Global System for Mobile Communication) module can be used to send the signal over a mobile in a fixed frequency to other mobile phone connected with the receiver.

In between 1915 and 1920 electrical home appliance introduced. The smart home`s history can be easily traced back to the early turn of the century, where electrical and telephone wiring were installed in new houses. Integrated smart home infrastructure was usually built by hobbyist in the 1960s, built it was not until 1984 the term "Smart Home" was coined by the American Association of Home Builders. General Electric company was one of the first pioneers to develop a series of products made for smart automated homes in the mid 60 's, these products included portable automatic dish washers and microwaves.

To increase the performances of a smart automated house, lots of research is going on. For an example; The 
Aware Home Research Initiative (AHRI) at Georgia Institute of Technology is an interdisciplinary research endeavor aimed at addressing the fundamental technical, design, and social challenges for people in a home setting [8].

\section{METHODOLOGY}

There are two parts in our project. They are the security system and the load controlling system. In the security system we use several sensors such as temperature sensor, fire detector sensor, motion sensor. In the load controlling system we use relay to on or off the load. We have used GSM module to send message to a subscriber identification number about security purpose [9]. We have also used this GSM module to control load from remote area. The equipments that we have used in the whole project have been designed in the Proteus software. Each part of our project has been discussed in details.

\section{A. Temperature sensing unit}

This unit monitors real time temperature data from two rooms continuously. Every room has its setting temperature. Above this setting value, the microcontroller sends message to the user's mobile phone that the temperature is high.

We have used Thermistor (10K) as temperature sensor with a negative temperature coefficient. Good choice for temperature sensing applications [10], [11], [12].When temperature raises the resistance of Thermistor decreases.

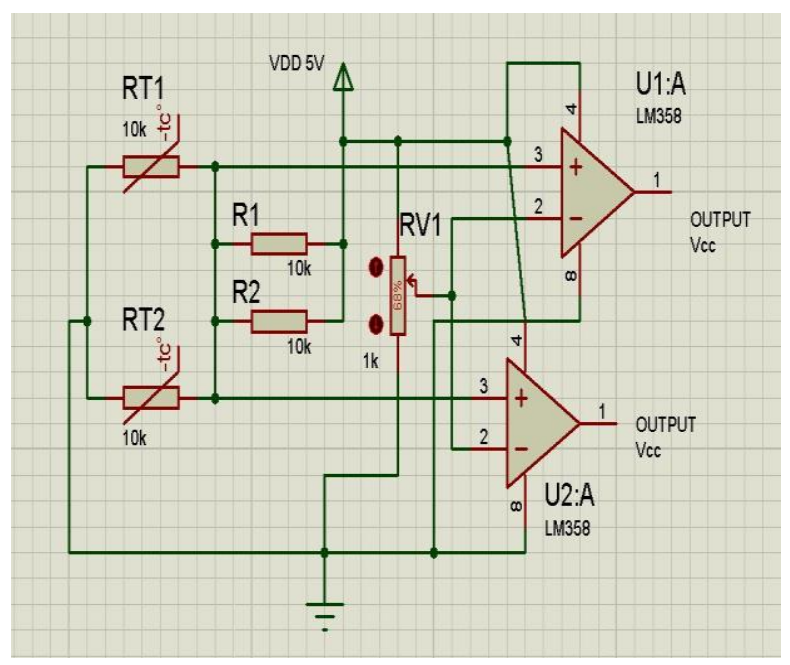

Fig.1. Temperature sensing circuit

We have used comparator to set the reference value. Below the reference value, comparator output is high and above the reference value comparator output is low. Then the output of the comparator has been sent to the microcontroller. Then the microcontroller processes the taken from the comparator and sends a message to user's mobile phone as it has been programmed.

\section{B. Fire detector unit}

This unit has been used to detect flame in the corresponding room. Fire detector has the range of detection with the wavelengths from $760 \mathrm{~nm}$ to $1100 \mathrm{~nm}$ and the detection angle can reach $60^{\circ}$. When infrared wavelengths near $940 \mathrm{~nm}$, it will reach the maximum sensitivity [13], [14].When flame is found within this range, the microcontroller takes action to send message to user's mobile phone number.

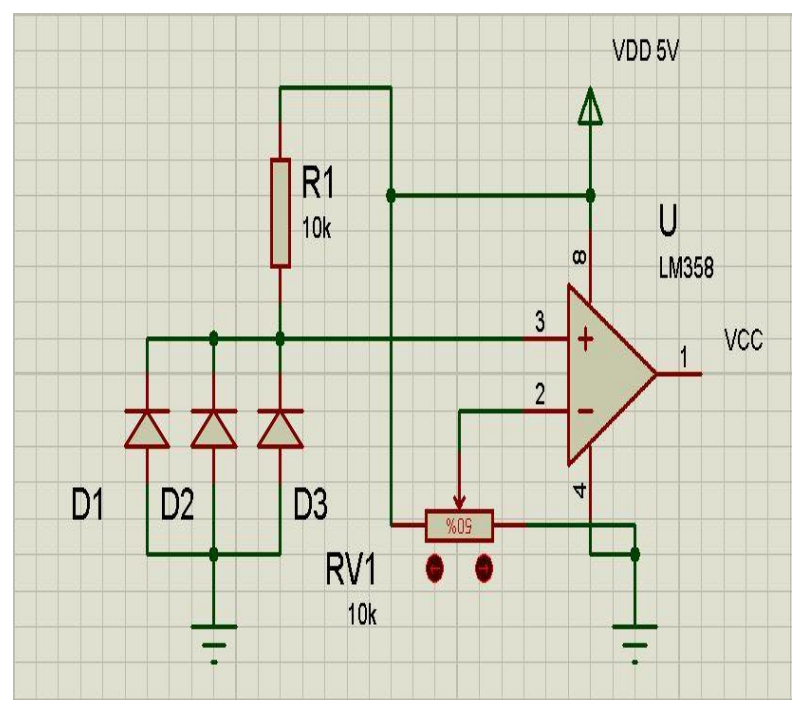

Fig.2. Fire detector circuit

When there is no flame, comparator output is high. When flame is found, comparator output is low. We have sent this comparator output value to the microcontroller input. Then microcontroller take necessary decision by reading the comparator output and send message to the users mobile phone.

\section{Motion detector \& Lock system unit}

The motion sensor gives digital output which has been used as microcontrollers input. When motion has been detected, motion detector gives logical one to the microcontroller. Then microcontroller takes necessary decision by reading the detector output. As a motion sensor we used PIR sensor which allow you to sense motion, almost always used to detect whether a human has moved in or out of the sensor's range. They are often referred to as PIR, "Passive Infrared", "Piezoelectric", or "IR motion" sensors. PIRs are basically made of a piezoelectric sensor (which you can see above as the round metal can with a rectangular crystal in the centre), which can detect levels of infrared radiation. The PIR sensor itself has two slots in it; each slot is made of a special material that is sensitive to IR. The lens used here is not really doing much and so we see that the two slots can 'see' out past some distance (basically the sensitivity of the sensor) [15], [16].

In lock system, simple mechanism has been used. When a key has been inserted into the lock, two wires are connecting and give 5 volt to the microcontroller input port. Then microcontroller takes necessary decision by reading the input port. When key has been inserted, logic high input to the microcontroller pin. Then 
microcontroller prepares to send message to user's mobile phone number via GSM module [17], [18], [19].

\section{Load controlling system}

In this project the main and first priority unit is load control which has been interfaced with microcontroller. Load can be turned on or off by sending message from mobile phone. In our project we have controlled five loads via microcontroller and GSM module [20]. We can also receive update of which load is on or which load is off if we want to know it.

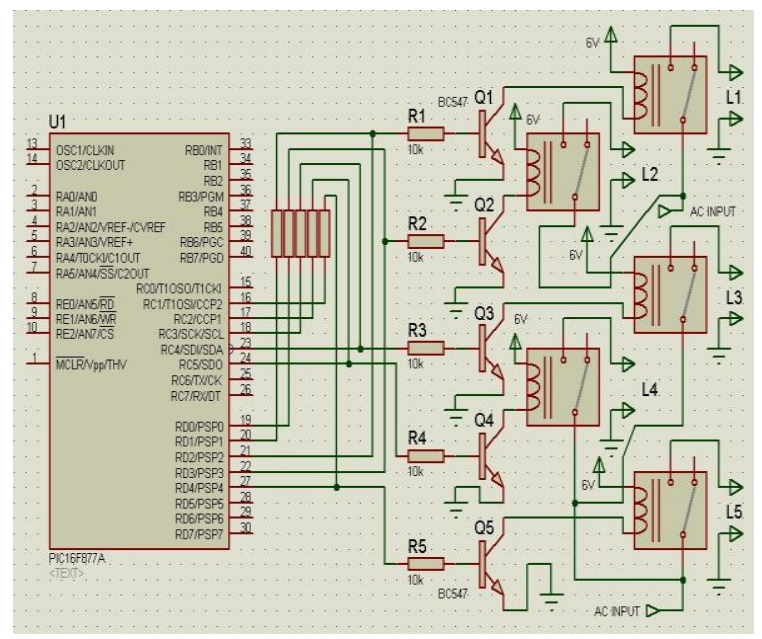

Fig.3.

Table 1. Message command for load control

\begin{tabular}{|c|c|}
\hline Command & Response \\
\hline A & Load 1 ON \\
\hline B & Load 2 ON \\
\hline C & Load 3 ON \\
\hline D & Load 4 ON \\
\hline E & Load 5 ON \\
\hline a & Load 1 OFF \\
\hline b & Load 2 OFF \\
\hline c & Load 3 OFF \\
\hline d & Load 4 OFF \\
\hline e & Load 5 OFF \\
\hline X & All Load OFF \\
\hline Y & All Load ON \\
\hline S & Send status about load on or off \\
\hline
\end{tabular}

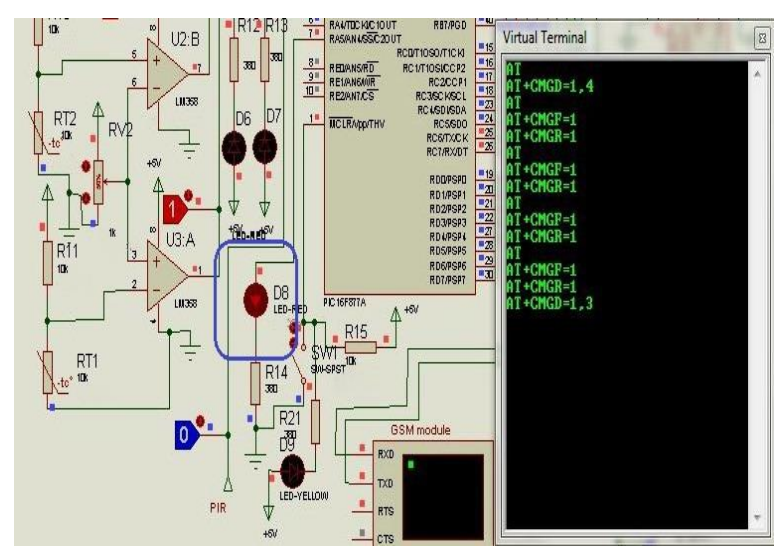

Fig.4. Command shown in virtual terminal

\section{RESULTS AND DISCUSSIONS}

In this section we have been discussed about the physical construction and operations of the project. There is GSM module which receive message and send data into microcontroller. Microcontroller read message and take necessary action to control the loads. GSM module also send message to mobile unit when temperature is high or flame is detected or motion is found of human body. This module also sends status about load and sensor to the mobile unit when user wanted to know the status.

\section{A. Command sends to GSM module}

Microcontroller send different type of command to operate the GSM module such as initialization module, delete message, read message, set text mode, send message etc. At first GSM modem is initialized and set the baud rate. Then it deletes all messages from SIM. When GSM module is ready for receive data, the red LED (D8) is turn on. Now it is ready for receive message and send data to microcontroller.

\section{B. Operation of Temperature sensor}

When temperature is below the reference value which has been set by the variable resistor, comparator output is high and above the reference value comparator output is low. We have been used comparator output in microcontroller input. In Proteus software simulation we have used logic toggle to set pin low or high.

When logic toggle pin make zero, the red LED is on, connected to output of temperature sensor which means temperature is high. Then microcontroller sends message to user's number (01770044141) which is shown in the fig 2 .

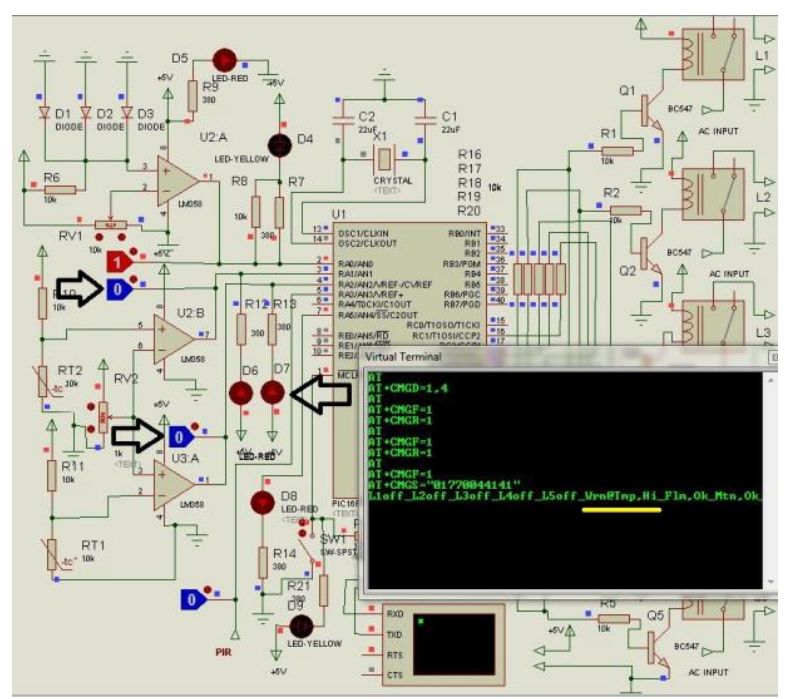

Fig.5. Software simulation of temperature sensor 


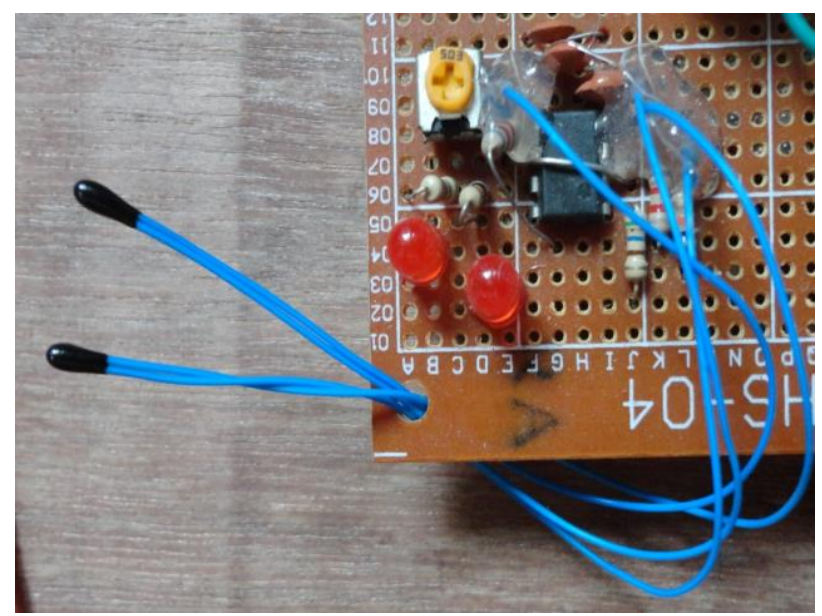

Fig.6. Hardware simulation of temperature sensor

Two red LED is off when temperature is below to the reference value. When temperature increases and above to the reference value, LED is on and microcontroller input is zero and it prepares for send message of warning.

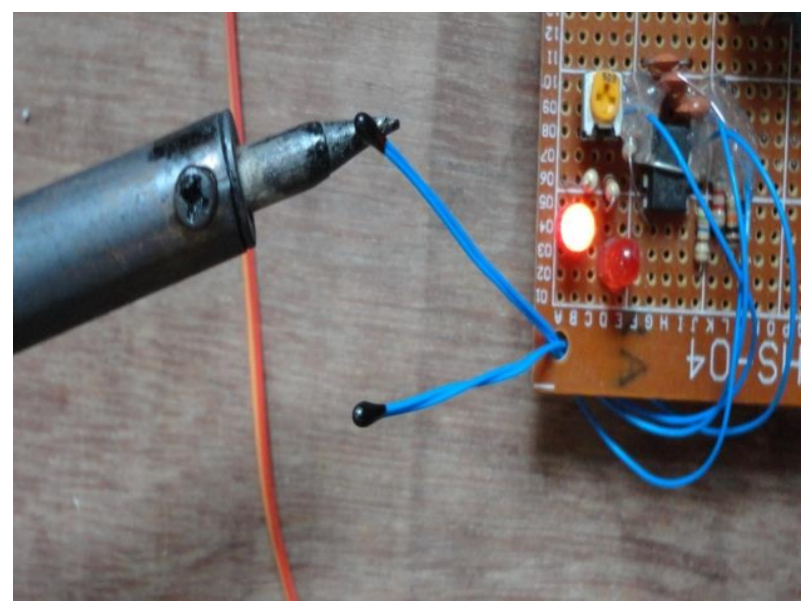

Fig.7. Temperature of sensor 1 is increase

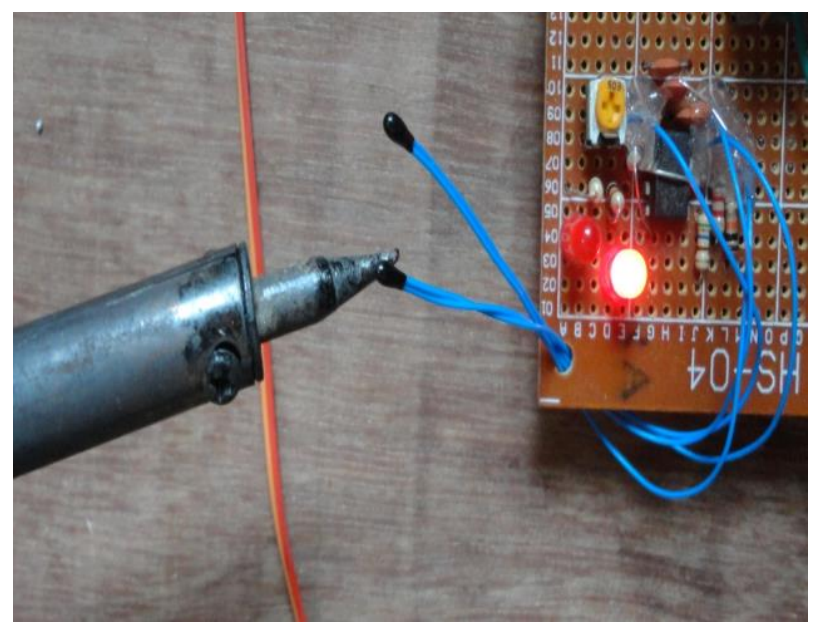

Fig.8. Temperature of sensor 2 is increase

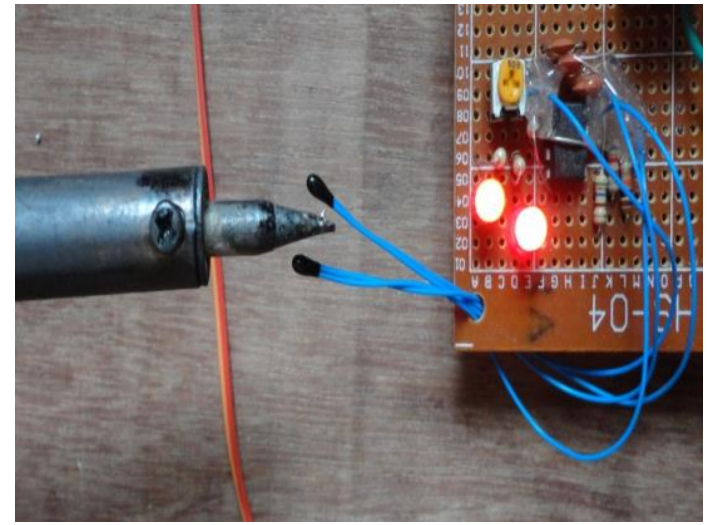

Fig.9. Temperature of both sensors is increase

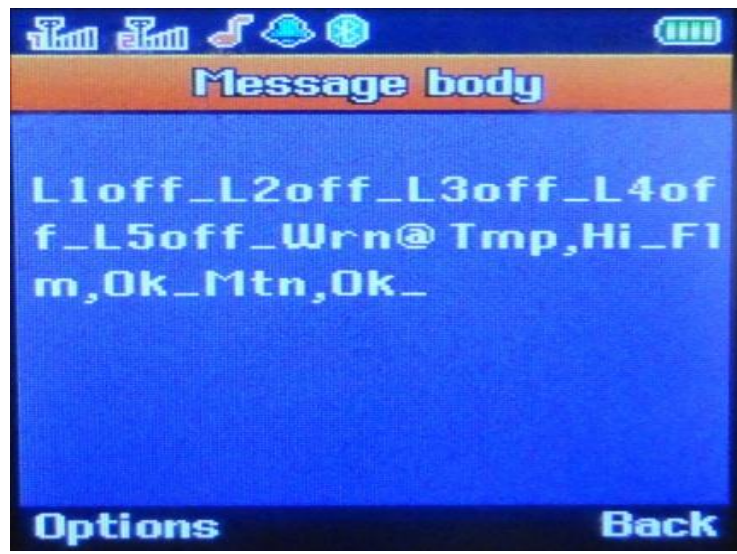

Fig.10. Temperature warning message

\section{Operation of fire detector}

Flame sensor is like a diode. At first we have set the detecting range of sensor using variable resistor. Red LED is the power LED using in the circuit. When fire has been detected in the detecting area then yellow LED is on. Clear the microcontroller pin and then microcontroller send message to the user's mobile phone number.

The whole process has been done in software simulation by logic toggle pin by making zero. When fire has been detected by the sensor then the yellow LED is turned on and the microcontroller gets logic zero and sends a message to the user's mobile phone number.

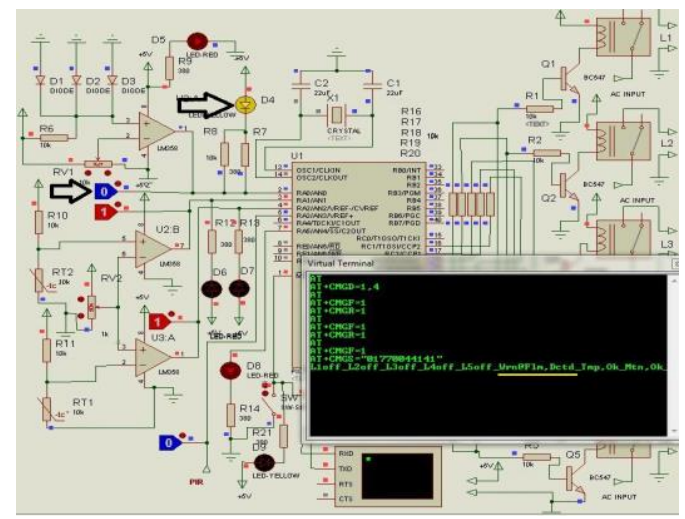

Fig.11. Software simulation 
When fire has been detected by the sensor then the yellow LED is turned on and the microcontroller gets logic zero and sends a message to the user's mobile phone number.

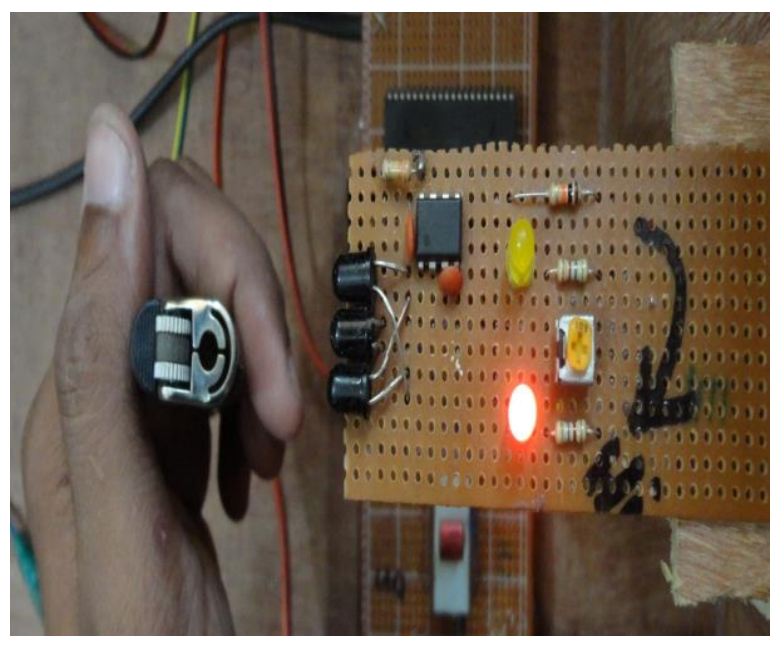

Fig.12. When fire is not present

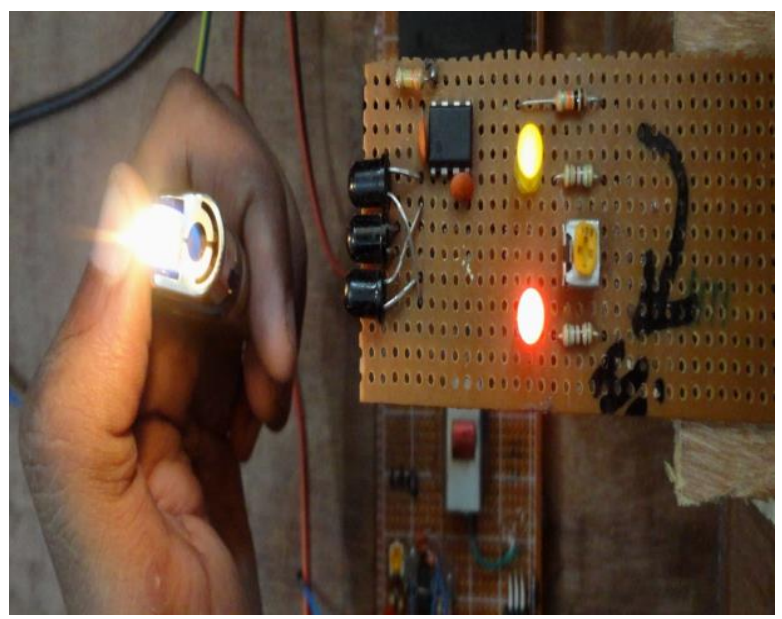

Fig.13. When fire is detected

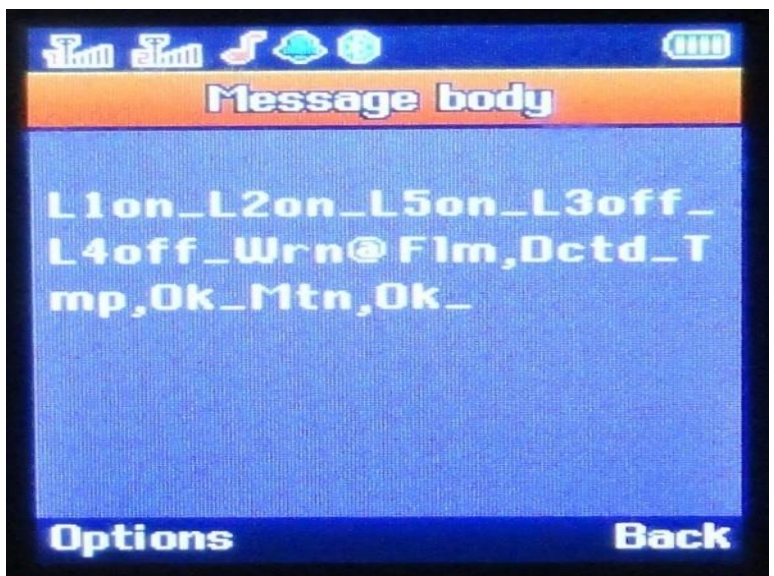

Fig.14. Fire detection warning message

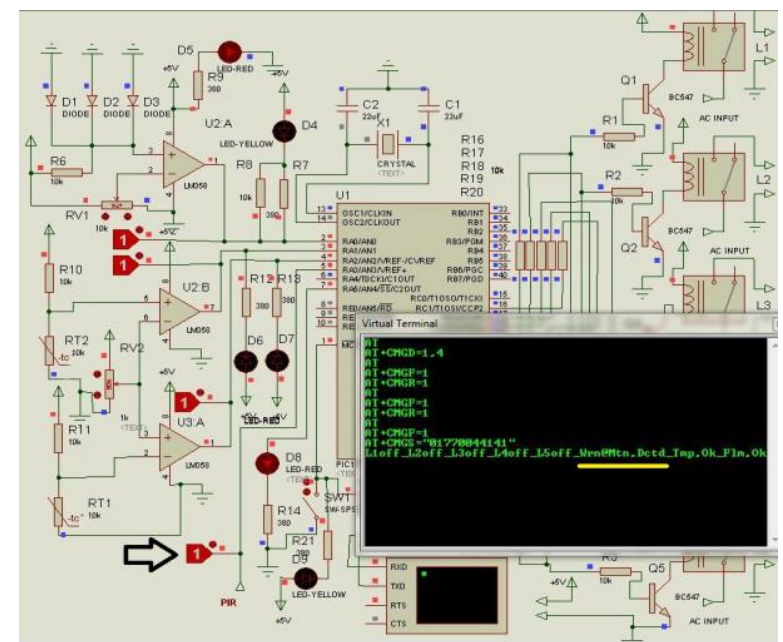

Fig.15. Software simulation of motion sensor

\section{Operation of Motion detector \& Lock system}

When motion has been detected the microcontroller sends message to the user's mobile phone number.

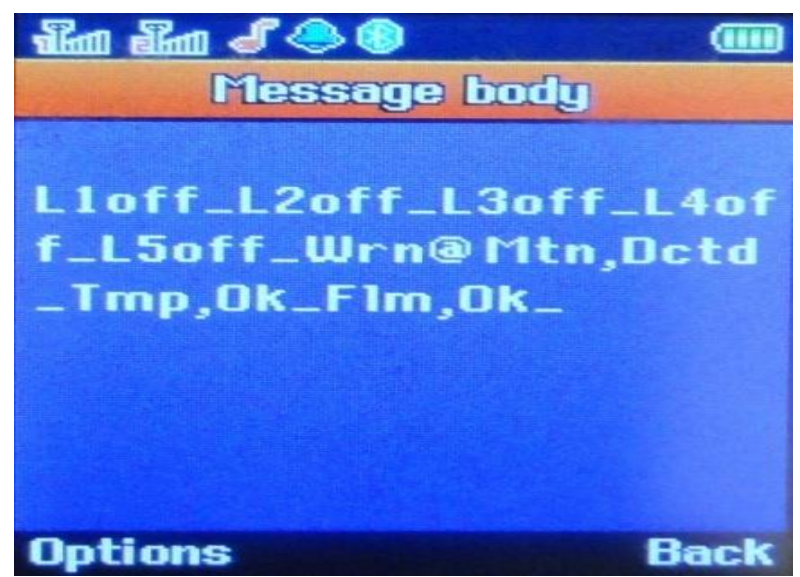

Fig.16. Motion detection warning message

In the lock system we have used two plates where we have provided a voltage difference. One plate is connected to positive terminal and another plate is connected to the microcontroller. When the key has been inserted to the lock these plates make a contact with each other then microcontroller gets data one and a message has been sent to the user's mobile phone number.

\section{E. Operation of Load controlling system}

In our project we can control each and every load individually. In this system we can turn on or off every load by sending a message from the user's mobile phone number. Such as for load 1, if we want to turn on we have to send a message writing the code 'A' and on the other hand if we want to turn off we have to send a message writing the code 'a'. Rest of the loads can be controlled in this way. 


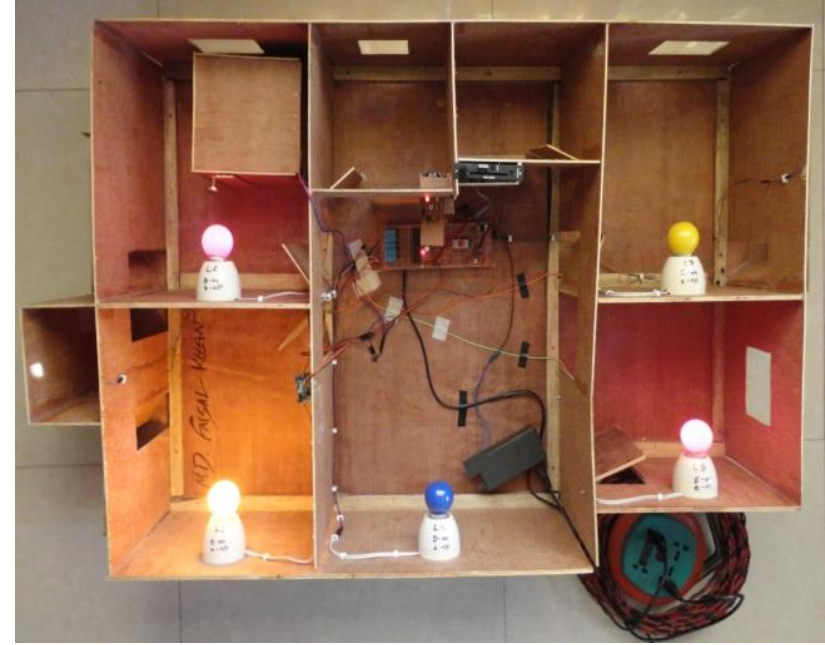

Fig.17. Load controlling system

There is another feature in the load controlling system and that is, if we want to know the loads present condition we have to send a message writing the code 'S'. This code will be received by the GSM module and a reply message will be sent to the user's mobile phone number that which loads are on and which loads are off.

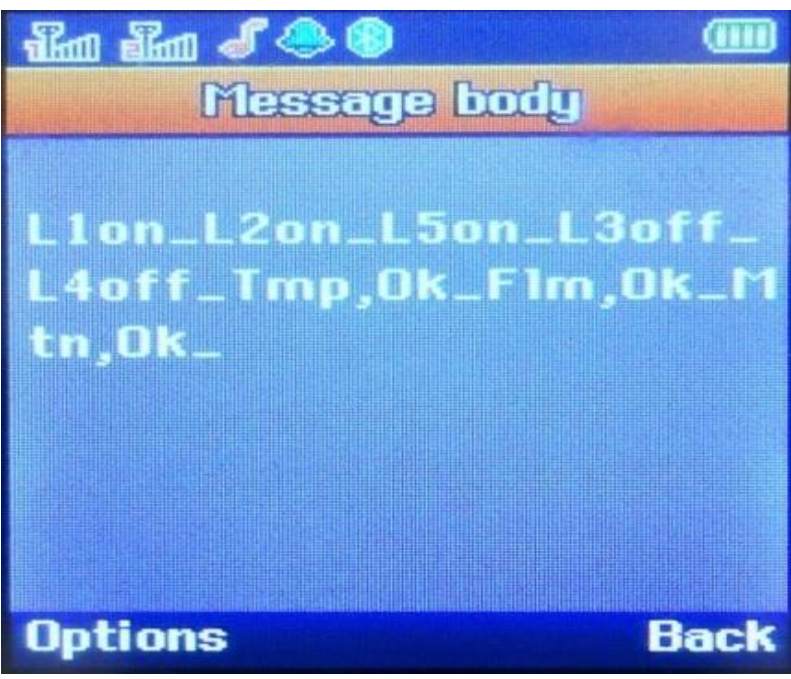

Fig.18. Status of Load

\section{F. Implementation with Remote Controller}

This project also can be implemented with a remote controller where the remote controller will be used to turn on or off the house hold loads. The speed of the fan also can be varied with the help of remote controller.

\section{G. Implementation for security purpose}

For security purpose face detection and image processing technology can be used in this project. To turn ON or Lock down the whole system so that no one can operate anymore a password can be used which would be the image of the user. Also numeric and finger print can be used as a password with the help of keypad or finger print sensor which will provide a secured system for a user.

\section{H. Implementation of Heart Beat Sensor}

We can use heart beat sensor which will show the his her heart beat rate with the help of display. This feature can be also used for speed controlling of fan or for varying the temperature of the Air-conditioner. So that, the room achieves a comfortable atmosphere.

\section{Visitor Counting Sensor}

In this project we have used visitor counter and that will count the number of present visitors. Existing number of visitor will be shown in the display. The speed of the fan can be increased or decreased also the temperature of the air-conditioner can be varied as the number of visitors' increases or decreases to maintain a comfortable living condition for the visitors.

\section{CONCLUSION}

With advancement of technology things are becoming simpler and easier for us. Automation is the use of control systems and information technologies to reduce the need for human work in the production of goods and services. The communication of home is only through the SMS which has been tested with the mobile networks and is working on any mobile network. By this project we have stepped one step further to the future. The sensor based security system detects the motion and sends message to fire, police station and owner. There are various parameters which can be adjusted in this software. The developed GSM based security system gives good response to the sensor and sends SMS when it detects the fire or temperature is increased above desired level. Besides, it can send a message to the user for action when the owner is out of station and the home is locked which helps us to keep more secure of our home. Moreover, owner can control loads (on/off) automatically by mobile using GSM technology from anywhere. This project will have a large effect to the living standard of human being. In the system, a lot of other features can be added to the user's requirement depending upon the situation. A lot of things can be done in the project in the future but due to time limitations, this time it was not possible. This system can also be applicable in bank. If some emergency occurs, then the volt of the bank can be automatically locked down. Emergency fire service can also be done by this system. This system is practically easy to use and user friendly so it have a good future. It is cheap to build so it can be industrially produced and served in the market. Overall this project discusses the analysis, design and implementation of home automation.

\section{ACKNOWLEDGEMENT}

We would like to express our gratitude to our supervisor, Mr. A.H.M. Zadidul Karim who has the attitude and the substance of a genius, for the useful comments, remarks and encouragement helped us in all the times of study and analysis of the project in the pre and post research period. Without his guidance and persistent help this project would not have been come to 
fact. We would also like to thank our honorable dean and vice-chancellor who gave us the opportunity to do an extremely interesting project on the topic "Microcontroller based home security and load controlling using GSM technology". It helped us to pursue research in fascinating field and learn so much more about Microcontroller and its application.

\section{REFERENCES}

[1] E Wong "A Phone-Based Remote Controller for Home and Office Automation", IEEE Trans Consumer Electron, vol.40, No. 1, pp. 28- 33, 1995.

[2] J. Burroughs, "X-10 home automation using the PIC16F877A," Lamp, vol. 10, article 10, 2010.

[3] A. Z. Alkar, and U. Buhur, "An Internet Based Wireless Home Automation System for Multifunctional Devices," IEEE Transactions on Consumer Electronics, vol. 51, no. 4, pp. 1169-1174, 2005.

[4] Piyare, R., Tazil M., "Bluetooth based Home AutomationSystem using Cell Phone", IEEE 15th International Symposium on Consumer Electronics, pp. 192-195, 2011.

[5] Jayashri Bangali and Arvind Shaligram" Design and Implementation of Security Systems for Smart Home based on GSM technology", International Journal of Smart Home Vol.7, No.6 (2013), pp.201-208.

[6] Yuksekkaya, B., Kayalar, A.A., Tosun, M.B., Ozcan, M.K., Alkar, A.Z., "A GSM, Internet and Speech Controlled Wireless Interactive Home Automation System", IEEE Transactions Consumer Electronics, vol. 52, no. 3, pp. 837-843, 2006.

[7] Y. Zhao and Z. Ye, "A Low Cost GSM/GPRS Based Wireless Home Security System", IEEE Transactions on Consumer Electronics, vol. 54, no. 2, pp. 567-572, 2008.

[8] http://www.awarehome.gatech.edu/.

[9] INandeesh G S, IIB Srinivasalu Reddy, IIISunil Kumar K M Intelligent Security System for Industries by using GPS and GSM International Journal of Advanced Research in Computer Science \& Technology (IJARCST 2014) Vol. 2 Issue 1 Ver 2 Jan-March 2014.

[10] Temperature Measurement with a Thermistor and an Arduino G. Recktenwald, gerry@me.pdx.edu

[11] http://www.newark.com/betatherm/10k3a542i/Thermistor - Ntc10k-0-2deg-radial/dp/23M8117.

[12] Dogan Ibrahim, "Microcontroller Based Temperature Monitoring Control".

[13] http://en.wikipedia.org/wiki/Flame_detector.

[14] Holborn, P.G., Nolan, P.F., Golt, and J.: An Analysis of fatal unintentional dwelling fires investigation by London Fire Brigade between 1996 and 2000. Fire Safety Journal, 1-42, (2003).

[15] Motion Detection based on Multi Frame Video under Surveillance System-Neelam Patel.

[16] http://www.ladyada.net/learn/sensors/pir.html.

[17] Wu, Bing-Fei, Peng, Hsin-Yuan; Chen, Chao-Jung "A Practical home security system via mobile phones", WSEAS Transactions on Communications, v5, 2006, pp.1061-1066.

[18] GSM Based Home Automation with Security (Using Microcontroller) Dr. Shaik Meeravali 1, P. Sai Prasad 2 International Journal of Engineering Research \& Technology (IJERT) Vol. 2 Issue 9, September 2013ISSN: 2278-0181.
[19] J.G. Vinson etc., "Secure- Way an Affordable Home Security System". Proceedings, the Institute of Electrical and Electronics Engineers 28thAnnual 1994 International Carnahan Conference on Security Technology, IEEE, 1994, pp. 144-146.

[20] Pic controller based process control system using GSMRitesh Gupta, Mukti Awad.

Authors' Profiles

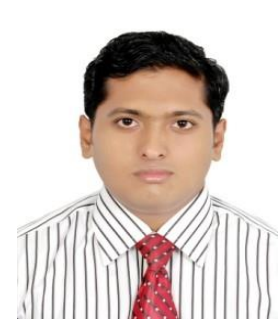

Mustafijur Rahman was born in the city Dhaka, Bangladesh in the year 1991. He received his B.Sc. Degree in Electrical and Electronic Engineering (EEE) from the department of EEE of University of Asia Pacific (UAP), Dhaka, Bangladesh in the year 2013. He is now working as an Engineer of EEE at Ablaze Solutions Ltd. His research area includes Microcontroller based system design and security purpose.

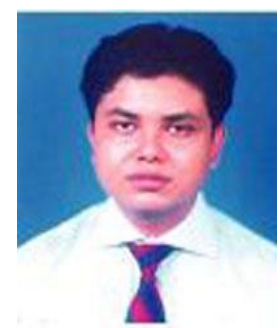

Zadidul Karim obtained his B.Sc. Engineering degree from Ahsanullah University of Science and Technology (AUST) in 2004. His undergraduate thesis title was "Design of a Two-Stage Open Loop Comparator using CMOS". $\mathrm{He}$ is doing his Masters degree in Bangladesh University of Engineering and Technology (BUET).

His current research interests are Detection and feature extraction of Atrial Tachyarrhythmia, Digital signal processing, Telecommunication, Wireless communication, Multimedia communication. $\mathrm{He}$ is an associate Member of IEEE, USA Microcontroller based system design.

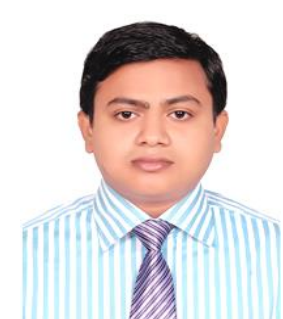

Sultanur Nyeem was born in the city Bogura, Bangladesh in the year 1990. $\mathrm{He}$ received his B.Sc.Degree in Electrical and Electronic Engineering (EEE) from the department of EEE of University of Asia Pacific (UAP), Dhaka, Bangladesh in the year 2013. He is now working as a service Engineer of EEE at Active energy Ltd. His research area includes Microcontroller based system design.

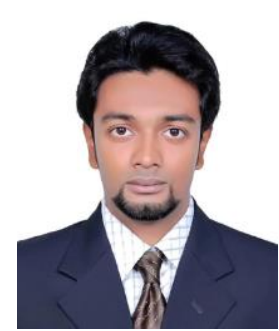

Faisal Khan was born in the city Dhaka, Bangladesh in the year 1991. He received his B.Sc.Degree in Electrical and Electronic Engineering (EEE) from the department of EEE of University of Asia Pacific (UAP), Dhaka, Bangladesh in the year 2013. His research area includes Microcontroller based system design. 


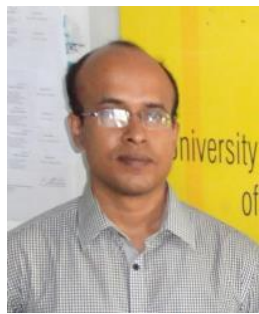

Golam Matin was born in the city Dhaka, Bangladesh in the year 1985. He received his B.Sc.Degree in Electrical and Electronic Engineering (EEE) from the department of EEE of University of Asia Pacific (UAP), Dhaka, Bangladesh in the year 2013. His research area includes Microcontroller based system design.

How to cite this paper: Mustafijur Rahman, A.H.M Zadidul Karim, Sultanur Nyeem, Faisal Khan, Golam Matin,"Microcontroller Based Home Security and Load Controlling Using Gsm Technology", IJCNIS, vol.7, no.4, pp.29-36, 2015.DOI: 10.5815/ijcnis.2015.04.04 